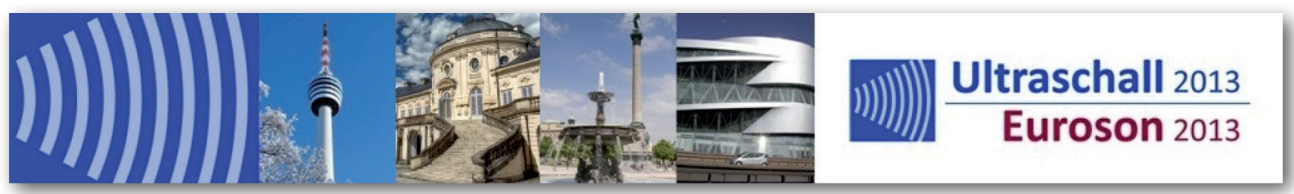

\title{
EUROSON 2014
}

The Israel Society of Ultrasound in Medicine (ISDUM) is proud to host the 2014 Annual Congress of the European Federation of Societies in Ultrasound in Medicine (EFSUMB) to be held at the David Intercontinental Hotel in Tel Aviv on May 26th28th. We are committed to offer a comprehensive program on the applications of diagnostic and interventional ultrasound in the different fields of medicine including the late technical developments and clinical researches, presented by worldwide known lecturers. We kindly invite you to visit our website at http://www.euroson2014.org/. The scientific program will include a full-day pre-congress courses on the topics of Musculoskeletal Ultrasound, Emergency Ultrasound, Abdominal Ultrasound and Breast Ultrasound, and two and a half congress days, split into Small Parts, Vascular, Interventional, Gynecology and Obstetrics, Urology, Gastrointestinal, Musculoskeletal, Emergency, New Technologies and others topics. Every session will be comprised of invited lectures and scientific papers. Hands-on workshops will be developed both in the pre-congress courses and during the congress. Scientific posters and an extensive technical exhibition will be offered all over the con-

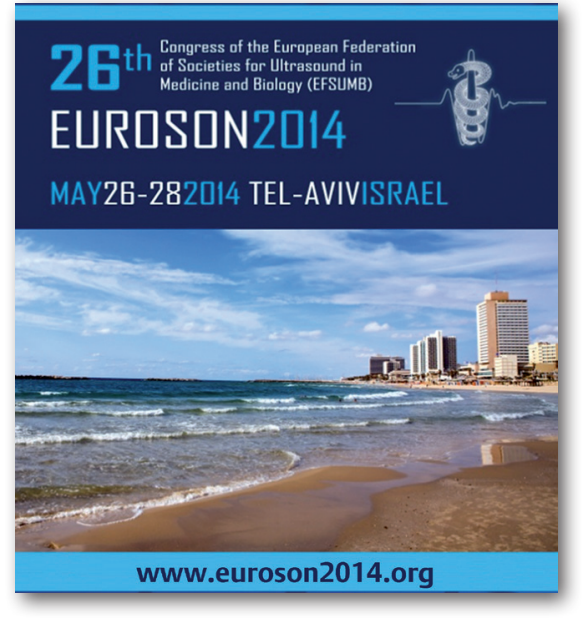

gress. The event will include tasteful meals included in the registration fees, served during coffee breaks and lunches, in the environment of David Intercontinental Hotel, situated on the beautiful Tel Aviv beach at the Mediterranean Sea. Besides, we invite you to take the opportunity to visit some of the multiple sightseeing, cultural, historical and religious sites in Israel through organized trips offered by our Organizing Company (Paragon-Dan Kinusim). We look forward to seeing you in Tel Aviv, the city that never sleeps! 